\title{
The Rising Importance of Pre-Analytical Phase in Medical and Research Laboratory, A New Challenge in the Omics Era
}

\author{
Guillaume Grzych ${ }^{1 *}$ and Ambily Sivadas ${ }^{2}$ \\ ${ }^{1}$ Univ Lille, Inserm, CHU Lille, Institut Pasteur de Lille, France \\ ${ }^{2}$ Division of Nutrition, St. John's Research Institute, St. John's National Academy of Health Sciences, Bangalore, India
}

*Corresponding author: Guillaume Grzych, Univ Lille, Inserm, CHU Lille, Institut Pasteur de Lille, U1011- EGID, F-59000 Lille,

France

\begin{tabular}{|c|c|}
\hline ARTICLE INFO & Abstract \\
\hline Received: 幽 April 30, 2020 & Laboratory analysis involves three main phases: pre-analytical, analytical and post \\
\hline Published: May 11, 2020 & $\begin{array}{l}\text { analytical. For a long time, analytical and post-analytical phases were deemed important } \\
\text { in medical biology. However, in the last few years, there is growing awareness about pre } \\
\text { analytical aspects and issues making it the new major challenge in medical laboratory. }\end{array}$ \\
\hline $\begin{array}{l}\text { Citation: Grzych G, Sivadas A. The Rising } \\
\text { Importance of Pre-Analytical Phase in } \\
\text { Medical and Research Laboratory, A New } \\
\text { Challenge in the Omics Era. Biomed J Sci \& } \\
\text { Tech Res 27(4)-2020. BJSTR. MS.ID.004523. }\end{array}$ & $\begin{array}{l}\text { Pre analytical phase encompasses a large range of variables that are associated with } \\
\text { patient characteristics, sample collection and sample processing. Pre analytical phase is } \\
\text { of paramount importance in medical diagnostics, but it continues to be underestimated } \\
\text { in research and clinical trials. A paradigm shift in the quality management of pre } \\
\text { analytical phase is overdue, especially with the increase of clinical omics application } \\
\text { such as metabolomics. }\end{array}$ \\
\hline
\end{tabular}

Keywords: Pre-Analytical; Medical Laboratory; Clinical Chemistry; Bias; Omics; Metabolomics

\section{Editoral}

Laboratory practice is divided into three broad phases: preanalytical, analytical and post analytical, that require equal attention towards ensuring overall quality management of laboratory diagnosis. There has been tremendous focus on the establishment of standardized protocols and best practice recommendations for the analytical and post analytical phases. However, there is a dearth of standards for the pre-analytical phase, which is considered the most error-prone and is often underestimated. The primary factors associated with pre analytical errors are linked to patient variables, sample collection and processing (Figure 1). Firstly, patient characteristics may influence pre analytical phase such as feeding state [1] or gender [2]. Physiological changes could promote some pre analytical events such as cell lysis in the form of hemolysis $[3,4]$ or leukocyte lysis that could be related to the type and levels of blood cells or even some hematological disorders [57]. Physiological changes could also modulate other measurements such as calcium influenced by internal $\mathrm{pH}$ and albumin concentrations that could complicate medical interpretation and diagnosis $[8,9]$. Drug intake could also influence measurements of certain parameters by analytical disruption or by physiological modulation [10,11]. Secondly, sample collection method could influence laboratory results. Even the degree of local tissue hypoxia during the application of a tourniquet could be influential [12]. In clinical chemistry, collection tubes contain additives that could influence measurement, choice of serum or plasma [13] and modify numerous variables such as turnaround time [13] and stability [14]. This emphasizes the need for performing validation studies in case of modification of routine additives $[15,16]$. 


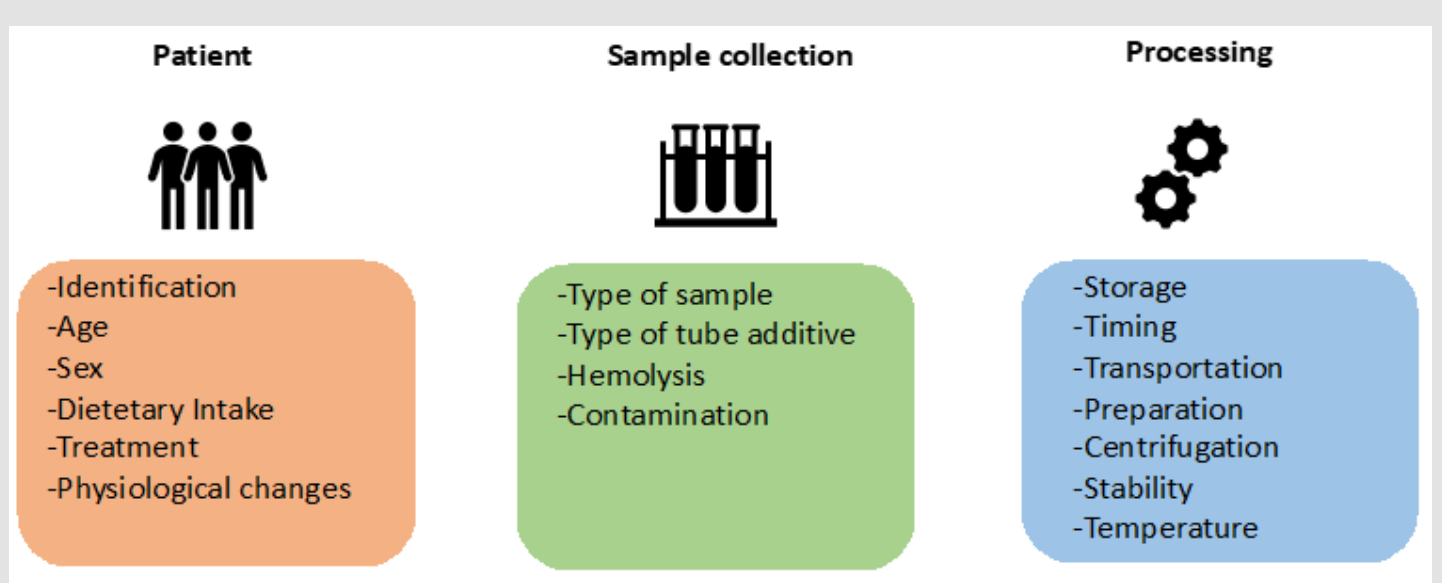

Figure 1: Summary of pre analytical phase and the main variables that may affect laboratory results.

Tube additives can also contaminate the sample. For example, EDTA contamination leads to false elevation of potassium, decrease of calcium and acidification of sample [17,18]. Finally, sample processing comprises other variables such as stability $[14,19]$, sample preparation, centrifugation conditions, transport temperature or storage that must be controlled to avoid false results $[20,21]$. In summary, measurement of pre analytical errors and subsequent quality management using standardized protocols are currently essential in medical biology but it should also be extended to the field of research given the increase in clinical omics applications [22]. The use of metabolomics particularly warrants more vigilance to pre-analytical issues. Indeed, metabolomics is the study of highly unstable and dynamic biomolecules, metabolites which can be influenced by all the variables described above [23]. In addition to experimental considerations to limiting sources of variation and the choice of instrumentation for analysis, pre analytical issues need to be carefully considered. The most studied metabolite, glucose, presents a classic case where its levels are influenced by physiological changes in the form of cell counts [5] or tube additives that modulate stability [14]. These findings on glucose may be extrapolated to substantial inconsistencies while performing large-scale metabolome analysis. It is imperative that sufficient rigor be applied to ensure robust experimental designs in metabolomics studies that carefully consider patient characteristics to avoid inter-group bias (e.g. drugs, diseases). Ample emphasis must be placed on standardization of sample collection, transport and storage protocols along with downstream sample processing as they could significantly impact pre-analytical errors $[12,24,25]$. Identification and monitoring of robust quality indicators of the pre analytical phase is necessary for streamlining the quality management process. Continuous tracking and systematic reporting of pre-analytical quality indices will facilitate high quality, reproducible experimentation and data generation. It will also enable efficient harmonization of protocols in large multicenter metabolomics studies and also promote better data sharing and re-use of metabolomics data. To conclude, responsible research calls for serious efforts towards minimizing pre analytical errors as it can lead to potentially misleading findings and conclusions.

\section{Competing Interests}

The authors declare that they have no competing interests.

\section{References}

1. Janssen K, Delanghe J (2010) Importance of the Pre-Analytical Phase in Blood Glucose Analysis. Acta Clin Belg 65(5): 311-318.

2. Franconi F, Rosano G, Campesi I (2005) Need for gender-specific preanalytical testing: The dark side of the moon in laboratory testing. Int J Cardiol 179: 514-535.

3. Koseoglu M, Hur A, Atay A, Cuhadar S (2011) Effects of hemolysis interference on routine biochemistry parameters. Biochem Medica 21(1): 79-85.

4. Duhalde H, SkogöJ, Karlsson M (2019) Point-of-care hemolysis detection in blood gas specimens directly at the emergency department. Scand J Clin Lab Invest 79(5): 283-287.

5. Grzych G, Roland E, Beauvais D, Maboudou P, Lippi G (2019) Leukocytosis interference in clinical chemistry: shall we still interpret test results without hematological data? J Med Biochem.

6. Grzych G, Pekar JD, Maboudou P, Lippi G (2019) Leucocytosis-induced plasma hyperkalaemia in samples conveyed by a pneumatic transport system: tips and tricks. Br J Haematol.

7. Grzych G, Roland E, Lezier D, Beauvais D, Maboudou P, et al. (2019) Transport par pneumatique et fausse hyperkaliémie par leucocytose: une étude rétrospective. Ann Biol Clin (Paris) 77(3) : 281-286.

8. Pekar JD, Grzych G, Durand G, Haas J, Lionet A, et al. (2019) Calcium state estimation by total calcium : the evidence to end the never-ending story. Clin Chem Lab Med CCLM.

9. Grzych G, Pekar JD, Durand G, Deckmyn B, Maboudou P, et al. (2019) Albumin-Adjusted Calcium and Ionized Calcium for Assessing Calcium Status in Hospitalized Patients. Clin Chem.

10. Martinello F, Da Silva EL (2006) Ascorbic acid interference in the measurement of serum biochemical parameters: In vivo and in vitro studies. Clin Biochem 39(4): 396-403.

11. Grzych G, Lopez B, Pekar JD (2019) Increased Triglycerides in a Child. Clin Chem 65(9): 1180-1181.

12. Cengiz M, Ulker P, Meiselman HJ, Baskurt OK (2009) Influence of tourniquet application on venous blood sampling for serum chemistry, hematological parameters, leukocyte activation and erythrocyte mechanical properties. Clin Chem Lab Med CCLM 47(6): 769-776. 
13. Plebani M, Banfi G, Bernardini S, Bondanini F, Conti L, et al. (2020) Serum or plasma? An old question looking for new answers. Clin Chem Lab Med CCLM 58(2): 178-187.

14. Grzych G, Pekar JD, Maboudou P (2019) Better Glucose Stability in Serum than in Plasma Samples after 12-h Stay at Room Temperature. Diabetes Technol Ther 21(7): 413-414.

15. Demonte D, Pucci M, Salvagno GL, Lippi G (2019) Can citrate plasma be used in exceptional circumstances for some clinical chemistry and immunochemistry tests? Diagnosis 6(4): 369-375.

16. Pekar JD, Carpentier T, Maboudou P, Grzych G (2019) Blood from heparin tubes is an acceptable alternative to assess hematocrit determination. Clin Chem Lab Med CCLM 57(10): e269-270.

17. Sharratt CL, Gilbert CJ, Cornes MC, Ford C, Gama R (2009) EDTA sample contamination is common and often undetected, putting patients at unnecessary risk of harm. Int J Clin Pract 63(8): 1259-1262.

18. Grzych G, Maboudou P, Brousseau T (2020) Factitious severe acidosis in a patient, preanalytical considerations and prevention. Clin Chem Lab Med CCLM 58(4): e100-101.

19. Lippi G, Salvagno GL, Lampus S, Danese E, Gelati M, et al. (2018) Impact of blood cell counts and volumes on glucose concentration in uncentrifuged serum and lithium-heparin blood tubes. Clin Chem Lab Med CCLM 56(12): 2125-2131.

ISSN: 2574-1241

DOI: $10.26717 /$ BJSTR.2020.27.004523

Guillaume Grzych. Biomed J Sci \& Tech Res

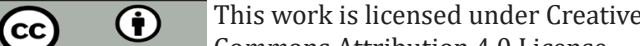

Submission Link: https://biomedres.us/submit-manuscript.php
20. Favresse J, Despas N, Boland L, Gruson D, Laterre PF, et al. Preanalytics of ammonia: stability, transport and temperature of centrifugation. Clin Chem Lab Med CCLM 56(3): e65-68.

21. Cadamuro J, MMM C, Leichtle AB, Kipman U, Felder TK, et al. (2018) Influence of centrifugation conditions on the results of 77 routine clinical chemistry analytes using standard vacuum blood collection tubes and the new BD-Barricor tubes. Biochem Medica 15: 28(1).

22. Lee JE, Kim YY (2017) Impact of Preanalytical Variations in BloodDerived Biospecimens on Omics Studies: Toward Precision Biobanking? OMICS J Integr Biol 21(9): 499-508.

23. Santos Ferreira DL, Maple HJ, Goodwin M, Brand JS, Yip V, et al. (2019) The Effect of Pre-Analytical Conditions on Blood Metabolomics in Epidemiological Studies. Metabolites 3: 9(4).

24. Kamlage B, Neuber S, Bethan B, González Maldonado S, Wagner-Golbs A, et al. (2018) Impact of Prolonged Blood Incubation and Extended Serum Storage at Room Temperature on the Human Serum Metabolome. Metabolites 8(1): 6

25. Wagner-Golbs A, Neuber S, Kamlage B, Christiansen N, Bethan B, et al (2019) Effects of Long-Term Storage at $-80{ }^{\circ} \mathrm{C}$ on the Human Plasma Metabolome. Metabolites 9(5): 99.

$\begin{array}{ll}\text { BIOMEDICAL } & \text { Assets of Publishing with us } \\ \text { RESEARCHES } & \text { - Global archiving of articles } \\ & \text { - Immediate, unrestricted online access } \\ & \text { - Rigorous Peer Review Process } \\ & \end{array}$

